\title{
O ciúme está relacionado ao amor? Contribuições de uma perspectiva analítico-comportamental ${ }^{*}$
}

\section{The jealousy is related to love? Contributions from a behavioral analytic perspective}

\section{¿Los celos se relacionán al amor? Aportes desde una perspectiva analítico conductual}

Nazaré Costa', Calíope Almeida ${ }^{2}$, Holga Gomes ${ }^{3}$, Juliana Lobato ${ }^{4}$, Ludmilla Gondim ${ }^{5}$, Mayra Silva ${ }^{6}$, Renata da Silva Pinheiro ${ }^{7}$, Thaís Almeida ${ }^{8}$, Valentina Almada Lima ${ }^{9}$

[1-9] Universidade Federal do Maranhão I Título abreviado: Ciúme e amor I Endereço para correspondência: Av. dos Holandeses, s/n. Ed. Porto Ravena, apt. 1301. CEP: 65075-650. São Luis/MA I Email: naza.pc@gmail.com

\begin{abstract}
Resumo: Ciúme e amor aparecem relacionados desde muito cedo na história da humanidade e ainda hoje observa-se essa relação. No entanto, praticamente não existem dados empíricos que apóiam a relação entre ambos. O artigo de Puente e Cohen, dois norte americanos, é um dos poucos que descreve estudos empíricos sobre essa relação. Como a presente pesquisa consistiu em uma replicação sistemática de um dos estudos desses autores, mantiveram-se os mesmos objetivos: verificar se as pessoas relacionam ciúme e amor e identificar se existe diferença nas respostas considerando o gênero do participante. A amostra foi constituída de 200 participantes, os quais foram apresentados a um texto descrevendo situações nas quais uma esposa interagia com um desconhecido e as reações dos maridos: um que apresentou ciúme frente à situação e o outro que não apresentou. Posteriormente responderam a uma escala Likert avaliando a reação de cada marido. De forma geral, confirmou-se a hipótese de que à medida que o comportamento da esposa se tornava mais provocativo, os participantes perceberiam a reação do marido ciumento como mais amorosa e favorável em comparação ao não ciumento. Os dados foram analisados a partir de conceitos como cultural, controle por regras e quadros relacionais.
\end{abstract}

Palavras-chave: ciúme, amor, cultura, análise do comportamento

* A pesquisa contou com auxílio da FAPEMA (Universal-00358/12). 
Abstract: Jealousy and love appear related since an early age in the history of humanity and such relationship has still been observed nowadays. However, there are virtually no empirical data to support the relationship between them. The article by Puente and Cohen, two North Americans, is one of the few that describes empirical studies about this relationship. As the present study consisted of a systematic replication from one of the studies by these authors, they were kept the same goals: to check if people relate jealousy and love and to identify if there is a difference in the responses considering the participant gender. The sample was consisted of 200 participants, who were presented to a text describing situations in which a wife interacted with a stranger and the husbands' reactions: one who had jealousy about the situation and the other who did not present. After, they should respond to a likert scale in which they evaluated the reaction of each husband. In general, it was confirmed the hypothesis that as wife's behavior got more provocative, the participants perceived the reaction of jealous husband as more loving and favorable compared to not jealous one. Data were analyzed from concepts such as culture, control by rules and relational framework.

Keywords: jealousy, love, culture, analysis of behavior.

Resumen: Celos y amor se muestran relacionados muy temprano en la historia de la humanidad y hoy dia aún se observa esta relación. Sin embargo, prácticamente no hay datos empíricos que apoyan esta relación. El artículo de Puente y Cohen, dos estadounidenses, es una de las pocas investigaciones empíricas que tratan del tema. Como el presente estudio fue una replicación sistemática de uno de los estudios destos investigadores, los objetivos fueran los mismos: comprobar si las personas relacionan celos y amor e identificar si hay diferencias en las respuestas teniendo en cuenta el sexo de los participantes. La muestra estuvo conformada por 200 participantes que leyeran a un texto que describía situaciones en las que una esposa interactuaba con un extraño y las reacciones de los maridos: un que tenían celos por la situación y el otro no presentaba. Enseguida ellos deberían responder a una escala likert en la que se evaluó la reacción de cada esposo. En general, se ha confirmado la hipótesis de que en la extensión que el comportamiento de la esposa se volvió más provocativo, los participantes percibirián la reacción del marido celoso como más amorosa y favorable en comparación con el no celoso. Los datos fueron analizados a partir de conceptos tales como cultura, control por regla y marco relacionales.

Palabras-clave: celos, amor, cultura, análisis de la conducta 
A literatura sobre ciúme ou comportamento emocional ciumento (termo proposto por Costa, 2009, em substituição ao termo ciúme ${ }^{1}$ ) tem privilegiado estudos acerca do que se denomina ciúme romântico (Bevan \& Samter, 2004), os quais, de certo modo, apontam para uma possível relação entre comportamento emocional ciumento e amor.

$\mathrm{Na}$ história da humanidade identifica-se que ambos aparecem relacionados desde muito cedo. Costa (1998), por exemplo, afirma que no século XII existia o "Código do Amor", o qual retratava as regras vigentes desse século e onde se observa que o comportamento emocional ciumento era relacionado ao amor em três dos mais de trinta itens que o compõe: "2. Quem não é ciumento não sabe amar"; "21. Pelo verdadeiro ciúme, a afeição do amor sempre cresce"; "22. Da suspeita e do ciúme que deriva dela, o amor sempre cresce" (p. 47).

Longe de ser uma relação encontrada apenas no passado, pode-se afirmar que ela ainda se faz presente na cultura brasileira, difundida em letras de músicas populares, telenovelas que frequentemente propagam a máxima que "o ciúme é o tempero do amor" e até mesmo em definições do termo ciúme, como a encontrada no Novo Dicionário Aurélio de língua portuguesa: "1. Sentimento doloroso que as exigências de um amor inquieto, o desejo de posse da pessoa amada, a suspeita ou a certeza da sua infidelidade fazem nascer em alguém, zelos" (Ferreira, 1999, p. 482, itálico acrescentado).

Como afirmou Ferreira-Santos (2003), na cultura ocidental é comum encontrar muitos indivíduos que fazem apologia ao ciúme em virtude desse evento ser visto como uma prova de amor. Em suas palavras "Para nós, brasileiros, com nossa herança latina, católica ou judaico-cristã, sentir ciúme faz parte do amor e, mais do que isso, do amor possessivo" (p. 30). Deste modo, pode-se dizer que a cultura então tende a esperar e a cobrar a expressão de comportamento emocional ciumento nas relações amorosas, especialmente quando se diz que se ama alguém.

1 Costa (2009) propôs este termo para ressaltar que ele refere-se a um conjunto complexo de comportamentos, tanto respondentes quanto operantes, que são interligados, mas que não mantêm entre si relações causais. Porém, o termo ciúme também será usado neste artigo.
Na literatura acadêmica o cenário não é muito distinto. Em diferentes referenciais teóricos da Psicologia, como a Evolutiva (Buss, 2000/2000) e a Psicanálise (Freud, 1921/1986; Pines \& Aronson, 1983), e em outras áreas do conhecimento (Cavalcante, 1995/1997; Stearns, 1989), encontra-se a relação entre comportamento emocional ciumento e amor. Entretanto, tal relação não é unanimidade entre os estudiosos. Para Gikovate (1998), por exemplo, mesmo que possa existir comportamento emocional ciumento relacionado ao amor, as pessoas que mais apresentam o primeiro não são necessariamente as que mais amam, e, muitas vezes, o amor nem mesmo está presente. Nessa perspectiva, não haveria então relação direta de dependência entre os dois sentimentos.

Apesar da cultura e da literatura acadêmica predominantemente relacionarem amor e comportamento emocional ciumento, se de fato eles estão relacionados é uma indagação para a qual praticamente não se tem dados empíricos.

No Brasil, os estudos de Lacerda e Costa (2013) e Pires, Abreu, Urbinati, Tilio e Almeida (2011) encontraram dados evidenciando que as pessoas relacionam o comportamento emocional ciumento ao amor. Para três mulheres, das 10 entrevistadas na pesquisa de Lacerda e Costa (2013), haveria um tipo de "ciúme" que sinalizava amor. Já na pesquisa Pires, Abreu, Urbinati, Tilio e Almeida, realizada com sete homens heterossexuais, os autores afirmaram que, para alguns (não especificam o N), o comportamento emocional ciumento foi concebido como prova de amor.

O artigo de Puente e Cohen (2003), até o momento, consiste no único artigo encontrado na literatura nacional e internacional que descreve três estudos empíricos que discutem a relação entre comportamento emocional ciumento e amor, em especial o Estudo I. Nas palavras dos autores, este estudo pretendeu "testar se as pessoas acreditavam na noção Agustiniana de que 'aquele que não tem ciúme não ama"' (p. 450).

Puente e Cohen (2003) realizaram o estudo em questão com 156 universitários, entre homens e mulheres, usando um questionário que os participantes respondiam de acordo com uma escala likert. Os autores confirmaram a hipótese segundo a qual à medida que o comportamento da mulher, 
em relação a outro homem, se tornava menos inocente (ou mais provocativo), os participantes considerariam a reação do marido ciumento como mais amorosa e favorável em comparação à reação do marido não ciumento.

Como este artigo descreve uma replicação sistemática do estudo supracitado, os objetivos delimitados foram os mesmos: verificar se as pessoas relacionam o comportamento emocional ciumento ao amor e identificar se existe diferença nas respostas considerando o gênero do participante.

\section{Método}

\section{Participantes}

Participaram da pesquisa 200 estudantes universitários, sendo 100 do sexo feminino e 100 do sexo masculino, maiores de 18 anos. O número de participantes, assim como a escolha por universitários, foram definidos com base na pesquisa original.

Usou-se como critérios de inclusão a maior idade, $\mathrm{o}$ aceite às condições descritas no Termo de Consentimento Livre e Esclarecido (TCLE) e a disponibilidade em participar da pesquisa. Para exclusão foi definido apenas deficiência visual, devido ao tipo de instrumento utilizado (impressão em folha A4). Supôs-se que a leitura do instrumento para os participantes com deficiência visual interferiria na privacidade de suas respostas e poderia influenciar sua opinião.

\section{Ambiente e Materiais}

A coleta de dados foi realizada em salas de aula, objetivando o mínimo de interferência externa possível, e com cadeiras suficientes para acomodar o(s) participante(s).

$\mathrm{O}$ instrumento utilizado consistiu em um questionário constituído de duas partes: 1) questões que solicitavam informações sobre o participante (idade, sexo, estado civil, e curso de graduação) e 2) 22 questões que deveriam ser marcadas de acordo com uma escala likert que variava de 1 a 5 pontos ausência ou nada; pouco; moderado ou moderadamente; muito; excessivamente ou completamente.

Apesar de no estudo original as escalas utilizadas variarem de 1 a 5 pontos e de 1 a 7 , no presente estudo, decidiu-se padronizar o intervalo da escala.

\section{Procedimento}

A coleta foi iniciada após aprovação no Comitê de Ética sob o Protocolo 23115016210/2011-99.

Os estudantes foram abordados individualmente ou em grupos, de até 10 pessoas, pelas discentes pesquisadoras que se identificavam como alunas regularmente matriculadas no Curso de Psicologia e como membros da equipe de pesquisa. Em seguida explicavam os objetivos da pesquisa e os critérios de participação.

Às pessoas que disseram ter interesse e disponibilidade em participar da pesquisa foi solicitado que assinassem o TCLE e, após, era informado que a pesquisa possuía alguns resultados de um estudo realizado anteriormente, em que se constatou que homens apresentam diferentes reações ao imaginarem sua esposa interagindo ou se relacionando com outro homem, e que se desejava a opinião de universitários sobre as respostas desses homens.

Em seguida era apresentado, de forma escrita, as três situações descritas a seguir: 1) inócua: homem andando na rua e vê sua esposa rindo e conversando com um homem que ele não conhece; 2) forte flerte: homem andando na rua e vê sua esposa sorrindo e conversando com um homem que ele não conhece. Durante a conversa ela toca na coxa do homem desconhecido, se inclina, sussurra algo em seu ouvido e depois o beija na bochecha; 3) traição: ao chegar em casa homem encontra sua esposa fazendo sexo com outro homem. Aos participantes, tais situações foram identificadas apenas como Situações 1, 2 e 3, respectivamente.

Após a apresentação de cada situação, os participantes leram sobre a reação de dois maridos: um que apresentou ciúme frente à situação de sua esposa interagir ou se relacionar com um homem desconhecido, e outro que não apresentou ciúme.

Utilizando uma escala de 1 a 5 pontos, os participantes respondiam no questionário o quanto: a) consideravam que cada marido amava sua esposa, b) desejava cuidar da esposa, c) queria estar com a esposa, d) respeitava sua esposa e e) tempo que o casamento ainda duraria (prognóstico). Por fim, era solicitado que os participantes classificassem nessa mesma escala o quão apropriada, aceitável e racional era cada reação dos maridos e o quanto consideravam cada marido como imaturo, inseguro e tolo. 
Análise dos Dados

Os dados obtidos foram analisados de modo que se efetuou uma comparação, para cada item, entre as respostas referentes à reação do marido ciumento e as referentes à reação do marido não ciumento. Foram levadas em consideração também as diferenças encontradas nas respostas para cada item de acordo com o gênero do participante.

A análise quantitativa foi feita utilizando o Statistical Package for Social Sciences (SPSS), na versão 15.0. Foram obtidas, assim como no estudo original, as médias e desvio padrão para quatro fatores: a) amor romântico (fator que incluiu respostas às questões o quanto ama, cuida e deseja estar com a esposa); b) compreensível (fator que buscava avaliar o quão compreensível era a reação do marido e no qual foram incluídas as respostas às questões quão apropriada, aceitável e racional era a reação); c) respeito e d) prognóstico ou duração da relação.

Foram efetuadas, ainda, análises correlacionais multifatoriais (MANOVA) e teste $t$. As correlações multivariadas foram realizadas entre as condições denominadas "ciúme" e não "ciúme" e as três situações (ou comportamento da esposa): inócua, forte flerte e traição. O teste $t$ foi utilizado quando os valores obtidos com a MANOVA não se mostraram significantes.

Apesar do uso de análises estatísticas, todos os dados foram discutidos a partir do referencial analítico-comportamental, mais especificamente com conceitos como cultura, controle por regras e quadros relacionais.

\section{Resultados e Discussão}

Nesta pesquisa buscou-se testar a hipótese segundo a qual à medida que o comportamento da mulher ou a situação se tornava mais provocativa, os participantes perceberiam a reação do marido ciumento como mais amorosa e favorável em comparação com a reação do marido não ciumento, comparando-se os resultados obtidos com os do Estudo I de Puente e Cohen (2003). Desse modo, só serão descritos os dados que visam responder essa hipótese, assim como se houve diferença entre as respostas de acordo com o gênero, também conforme o estudo replicado.
Por meio da correlação multifatorial entre a condição ciúme e não ciúme e as situações inócua, forte flerte e traição, tanto no estudo norte-americano $-F(2,304)=142.04, p<.001-$ quanto neste, a hipótese supracitada foi confirmada. Na presente pesquisa, na situação de traição foi encontrado $F(3,193)=62,39, \mathrm{p}<.001$, enquanto na de forte flerte obteve-se $F(3,194)=37,98 \mathrm{p}<0,001$ e na inócua $F(3,193)=10,158 \mathrm{p}<.001$.

A relação entre ciúme e amor encontrada no presente estudo, bem como no de Puente e Cohen (2003), é, possivelmente, controlada por regras sociais, fortemente difundidas em nossa cultura. $\mathrm{O}$ trabalho de Gondim (2013), por exemplo, mostra como letras de músicas nacionais relacionam explicitamente o comportamento emocional ciumento ao amor, como a canção "Ciúme de você", imortalizada na interpretação de Roberto Carlos, da qual se destaca o seguinte trecho: "Entenda que o meu coração/ Tem amor demais meu bem e essa é a razão/ Do meu ciúme, ciúme de você".

Assim, pode-se afirmar que regras que relacionam o "ciúme" ao amor costumam levar à expectativa e à cobrança, culturalmente impostas, de expressões do comportamento emocional ciumento em relações amorosas.

No que se refere ao fator que mede o quão compreensível era a reação do marido, o estudo de Puente e Cohen (2003) aponta que, na situação inócua, a reação do marido ciumento foi vista como não compreensível, enquanto essa mesma reação foi vista como mais compreensível nas condições de forte flerte e de traição $(F(2,304)=256.34$, $\mathrm{p}<$ .001). Da mesma forma, no presente estudo, nas condições mais provocativas (forte flerte e traição), observou-se que os participantes avaliaram como mais compreensível a reação do marido ciumento (forte flerte: $F(6,188)=22,078, \mathrm{p}<.001$ e traição: $F(6,187)=57,032, \mathrm{p}<.001)$. Nesse sentido, observa-se que o quão provocativa é a situação é uma variável determinante para a aceitação social do comportamento emocional ciumento. Isso provavelmente também pode ser explicado por regras sociais vigentes em nossa cultura, segundo as quais, em situações provocativas o comportamento emocional ciumento seria justificável e até mesmo aprovado, já que haveria "motivos" para a pessoa comportar-se dessa forma. 
Correlacionando as reações do marido (ciumenta e não ciumenta) à variável respeito, Puente e Cohen (2003) também encontraram que quanto mais provocativa era a situação, mais os participantes avaliavam o ciúme como indicativo de respeito em relação ao não ciúme, $F(2,302)=111.23, p<$ .001. Já na presente pesquisa, apesar dessa predição ter sido confirmada, uma vez que, na situação de traição, o ciúme foi mais associado pelos participantes ao respeito (valor de $t(199)=4,981, \mathrm{p}<$ .001), também observou-se que, na situação inócua, o não ciúme foi mais associado ao respeito pelos participantes $(t(199)=-8,207, \mathrm{p}<.001)$.

Verifica-se, dessa forma, que o respeito pode ter sido relacionado ao amor pelos participantes (relação esta também evidenciada em nossa cultura), na medida em que os resultados encontrados nesse terceiro fator se assemelham aos identificados no fator anterior, ou seja, para os participantes da presente pesquisa, quanto mais provocativa a situação, mais o marido ciumento ama e respeita a esposa. Entretanto, é importante chamar atenção que não apenas essa relação (amor, ciúme e respeito, em situações provocativas) foi encontrada neste estudo. A relação específica entre respeito e não ciúme, em situação menos provocativa (inócua), foi até mais evidente do que a anterior.

Assim, utilizando-se do conceito de quadros relacionais, nos quais estímulos são relacionados arbitrariamente e têm suas funções alteradas por participarem do mesmo quadro reacional (Hayes, Barnes-Holmes \& Roche, 2001), uma relação clara evidenciada no estudo de Puente e Cohen (2003) e confirmada nesta pesquisa provavelmente é: "Se o 'ciúme' está relacionado ao amor e o amor ao respeito (por exemplo), então, o 'ciúme' relaciona-se ao respeito". Logo, esses estímulos diferentes são enquadrados arbitrariamente, compartilhando funções e controlando respostas semelhantes, tais como a de aceitar e até incentivar comportamentos ciumentos no parceiro(a).

Considerando que, além dessa relação, outra equivalência foi encontrada: não ciúme e respeito em uma situação menos provocativa, pode-se associar tal dado à rejeição da presença do ciúme em situações consideradas culturalmente como inapropriadas, por exemplo, a situação inócua descrita neste estudo. Sendo assim, tanto a presença do ciú- me em situações como esta é vista como desrespeito, quanto a ausência do mesmo em situações pouco ou não provocativas é concebida como respeito.

No estudo de Puente e Cohen (2003) foi encontrado também que, de acordo com os participantes, a reação do marido ciumento em uma situação mais provocativa é indicativa de melhor prognóstico para o relacionamento $-F(2,292)=65.03, \mathrm{p}<.001)-\mathrm{em}$ comparação à reação do marido não ciumento. No presente estudo, embora os participantes também tenham indicado o comportamento do marido ciumento como melhor prognóstico, só o fizeram nas situações menos provocativas: inócua $F(1,198)=62,185$, p $<.001$ e forte flerte $F(1,198)=4,463 \mathrm{p}<.05)$.

Uma vez que os participantes desta pesquisa relacionaram o amor ao comportamento emocional ciumento e à compreensão e, mesmo que de forma mais discreta, ao respeito, esperava-se que, assim como no estudo original, os participantes considerariam a presença do comportamento emocional ciumento, em uma situação mais provocativa, como melhor prognóstico para o relacionamento. Os dados encontrados entretanto, somados aos de Puente e Cohen (2003), sugerem que a presença do ciúme, para o prognóstico de uma relação, seja uma variável importante (e talvez necessária) independentemente da situação ser mais ou menos provocativa. Acrescentando-se a isso, pode-se ainda supor que na situação de traição o ciúme seja uma variável menos relevante que a própria traição para a continuação do relacionamento, ou seja, se houve traição, o relacionamento provavelmente não continuará. Como afirmou Ferreira-Santos (2003), "o ciúme reside [ou pode estar relacionado] na dúvida, no medo, quando há a certeza da traição, o sentimento que aparece é outro" (p. 27).

Acerca do gênero, no estudo de Puente e Cohen (2003), foram encontradas diferenças significantes apenas para os fatores amor romântico $(F(2,304)=$ $5.49, \mathrm{p}<.005)$ e respeito $(F(2,302)=3.66, \mathrm{p}<.03)$, sendo que as diferenças foram mais significantes entre os participantes do gênero feminino.

Neste estudo, a diferença entre os gêneros foi analisada através do test $t$ para amostras independentes, que apontou para uma homogeneidade na maioria das interações, ou seja, as variâncias foram aproximadamente iguais para ambos os gêneros. Encontrou-se diferenças significantes para: a) gê- 
Tabela 1. Diferenças encontradas nas respostas para cada item de acordo com o gênero do participante

\begin{tabular}{llllll}
\hline Fator & Condição & Situação & $\mathbf{T}$ & Médias \\
& & & & Homem & Mulher \\
Amor romântico & Ciúme & Inócua & $\mathrm{t}(198)=-1,28, \mathrm{p}=0,20$ & $3,55(0,92)$ & $3,71(0,81)$ \\
Prognóstico & Ciúme & Traição & $\mathrm{t}(198)=-2,86, \mathrm{p}=0,005$ & $1,48(0,97)$ & $1,93(1,24)$ \\
Compreensão & Não Ciúme & Forte Flerte & $\mathrm{t}(198)=-, 633, \mathrm{p}=0,53$ & $2,66(0,50)$ & $2,61(0,65)$ \\
Respeito & Não Ciúme & Forte Flerte & $\mathrm{t}(198)=, 540, \mathrm{p}=0,59$ & $3,14(1,26)$ & $1,93(1,24)$ \\
\hline
\end{tabular}

nero e o fator amor romântico na situação inócua, condição ciúme; b) gênero e o fator compreensão na situação forte flerte, condição não ciúme; c) gênero e o fator respeito na situação forte flerte, condição não ciúme; d) gênero e fator prognóstico, na situação traição, condição "ciúme", conforme mostra a tabela 1 .

De forma geral, os dados de ambos os estudos sugerem que o gênero pode ser uma variável importante para discutir comportamento emocional ciumento e situação disparadora desse comportamento, embora homens e mulheres possam responder de forma semelhante. Tal hipótese pode ser corroborada com os dados de Costa e Barros (2008) que encontrarem algumas diferenças entre as respostas de homens e mulheres no que se refere a eventos que desencadeiam comportamento emocional ciumento, embora tais diferenças não tenham sido evidenciadas quando utilizado um teste estatístico (teste $t$ ).

\section{Considerações Finais}

Para a Análise do Comportamento, o ambiente é parte indispensável para a compreensão do comportamento humano (Skinner, 1953/1965). Ambiente físico e social (verbal) influenciam diretamente o modo de agir das pessoas, sendo o terceiro nível de variação e seleção (a cultura) essencial para a construção da história de vida de cada um (Skinner, 1953/1965), influenciando inclusive a construção do mundo psicológico de cada indivíduo (Skinner, 1945). Além disso, pode-se afirmar que a comunidade verbal não apenas afeta comportamentos de indivíduos isoladamente, já que, como apontado por Glenn (1989) e apoiado por Branch (2006), o comportamento verbal tem um papel fundamental também na instalação e manutenção das práticas culturais vigentes na sociedade.
Uma possibilidade de observar o controle da comunidade verbal sobre o comportamento das pessoas é a elaboração e o seguimento de regras. Neste último, estímulos verbais indicam, explícita ou implicitamente, como e até por quais motivos deve-se se comportar ou não de determinada maneira. O comportamento, portanto, é emitido, em um primeiro momento, independentemente de suas consequências imediatas embora as consequências atuem após sua emissão (Albuquerque, 2005).

Neste estudo, observou-se que as pessoas relacionaram amor e ciúme, o que pode ocorrer tanto devido a regras sociais presentes em nossa cultura quanto as consequências dispostas pela comunidade verbal quando esta relação é estabelecida por seus membros.

O controle por regras e contingências na ocorrência do comportamento emocional ciumento fica claro quando se observa a argumentação de Menezes e Castro (2001) segundo a qual um indivíduo pode emitir esse comportamento como forma de esquiva de estímulos aversivos por parte do grupo social caso ele não se comporte conforme o esperado (apresentando ciúme) diante de algumas situações. Desse modo, pode-se afirmar que quando um parceiro, em uma relação amorosa, não apresenta comportamento emocional ciumento, especialmente diante de uma situação mais provocativa (no caso deste estudo, a situação de traição), ele corre o risco de ser punido pela comunidade verbal. Esta, então, estabelece regras que tanto contribuem para a aceitação do ciúme como espera e incentiva a sua ocorrência.

É importante destacar que a relação estabelecida pela cultura entre amor e ciúme e a consequente aceitação e incentivo à emissão de comportamentos emocionais ciumentos podem gerar problemas nas relações amorosas quando, em algumas situações, 
alguém diz que ama e não sente ciúme do parceiro. A relação inclusive pode ser desfeita se o parceiro (que concebe o ciúme como sinal de amor) ficar apenas sob controle dessa regra.

Apesar da comunidade verbal relacionar ciúme e amor, à luz do referencial da Análise do Comportamento, tal formulação não se sustentaria, uma vez que um sentimento (evento comportamental) não se explica a partir de outro. Desse modo, essa relação pode trazer prejuízos, já que quando um sentimento é arbitrariamente associado a outro, ele poderá assumir a mesma função do evento o qual foi relacionado.

No estudo em questão o ciúme pareceu ter assumido as funções positivas do amor, o que poderia justificar, por exemplo, comportamentos violentos em relações amorosas quando o mesmo está presente, como evidenciaram os resultados de um dos estudos de Puente e Cohen (2003). Logo, estudos como estes têm função de alertar a sociedade para as contradições e até mesmo perigos que algumas de suas regras sociais podem ocasionar, por reforçarem relações totalmente arbitrárias que influenciam na sensibilidade a outras contingências em atuação.

Buscando-se aprimorar pesquisas com este foco, sugere-se incluir e analisar a influência da variável relacionamento amoroso (passado ou presente) por parte dos participantes. Essa variável seria relevante para verificar se esta parte da história de vida de cada um exerce controle na forma de responder as questões.

\section{Referências}

Albuquerque L. C. (2005). Regras como instrumento de análise do comportamento. In L. C. Albuquerque (org.) Estudos do comportamento (pp. 143-176). Belém, PA: Editora Universitária UFPA, 2005

Bevan, J. L. \& Samter, W. (2004). Toward a broader conceptualization of jealousy in close relationships: Two exploratory studies. Communication Studies, 55, 14-28.

Branch, M. N. (2006). Reactions of a laboratory scientist to a "think tank" of metacontingencies and cultural practices. Behavior and Social Issues, 16, 6-10.
Buss, D. M. (2000). A paixão perigosa: Por que o ciúme é tão necessário quanto o amor e o sexo $(\mathrm{M}$. Campello, Trad.). Rio de Janeiro, RJ: Objetiva. (Trabalho original publicado em 2000).

Cavalcante, A. M. (1997). Ciúme. In O ciúme patológico (pp. 23-24). Rio de Janeiro, RJ: Rosa dos Tempos. (Trabalho original publicado em 1995).

Costa, J. F. (1998). Sem fraude nem favor: Estudos sobre o amor romântico. Rio de Janeiro, RJ: Rocco.

Costa, N. (2009). Busca de definição operacional de ciúme: Uma construção teórica e empírica. Tese de doutorado não publicada, Universidade Federal do Pará, Belém, Brasil.

Costa, N., \& Barros, R. S. (2008). Test de definición y de una hipótesis sobre la diferencia de género bajo la óptica del análisis de la conducta. Terapia Psicológica, 26, 1, 15-25.

Ferreira, A. B. H. (1999). Novo Aurélio: O dicionário da língua portuguesa. Rio de Janeiro, RJ: Nova Fronteira.

Ferreira-Santos, E. (2003). Ciúme: O medo da perda. São Paulo, SP: Claridade.

Freud, S. (1986). Psicologia de grupo e análise do ego. In Obras Completas (pp. 79-154.), Vol. XVIII. Rio de Janeiro, RJ: Imago. (Trabalho original publicado em 1921).

Gikovate, F. (1998). Ciúme ou "ciúmes". In Ensaios sobre o amor e a solidão (pp. 103-140). São Paulo, SP: MG Editores.

Glenn, S. S. (1989). Verbal behavior and cultural practices. Behavior Analysis and Social Action, 7(1), 10-15.

Gondim, L. M. L. (2013). Da Bossa Nova à contemporaneidade: Identificando regras sociais relacionadas ao "ciúme" na música brasileira. Monografia, Departamento de Psicologia, Universidade Federal do Maranhão, São Luís.

Hayes, S. C., Barnes-Holmes, D., \& Roche, B. (2001). Relational frame theory: A post skinnerian account of human language and cognition. Kluwer Academic/ Plenum Publishing: New York.

Lacerda, L. \& Costa, N. (2013). Relação entre comportamentos emocionais ciumentos e violência contra a mulher. Revista Brasileira de Terapia Comportamental e Cognitiva, XV (3), 21-36. 
Menezes, A., \& Castro, F. (2001, setembro). O ciúme romântico: Uma abordagem analítico-comportamental. Trabalho apresentado no $\mathrm{X}$ Encontro Brasileiro de Medicina e Terapia Comportamental, Campinas, São Paulo.

Pines, A., \& Aronson, E. (1983). Antecedents, correlates, and consequences of sexual jealousy. Journal of Personality, 51 (1), 108-136.

Pires, M. R. M., Abreu, M. C., Urbinati, M. C., Tilio, R., \& Almeida, T. (2011). Representações dos homens heterossexuais acerca do ciúme contemporâneo. Trabalho apresentado no III Primeiro Simpósio Brasileiro de Família e Desenvolvimento Humano. Psicologia: Prevenção e Intervenção. Recuperado 13 março, 2013 de www.nac.ufpr.br/sbf2011

Puente, S., \& Cohen, (2003). Jealousy and meaning (or nomeaning) of violence. Personality and Social Psychology Bulletin, 29 (4), 449-460.

Skinner, B. F. (1945). The operational analysis of psychological terms. Psychological Review, 52, 270-277; 291-294.

Skinner, B. F. (1965). Science and human behavior. New York: The Free Press (Trabalho original publicado em 1953).

Stearns, N. P. (1989). Jealousy: The evolution of emotion in American history. New York e London: New York University Press. 